\title{
$\mathrm{AL} 1050$ 소재의 양·음각 점진성형 공법간 성형 정밀도 비교
}

\author{
이경부 ${ }^{\mathrm{a}}$, 오현만 ${ }^{\mathrm{a}}$, 강재관 ${ }^{\mathrm{b} *}$
}

\section{Forming Accuracy Comparison Between Positive and Negative Incremental Forming Al 1050}

\author{
Kyeong-Bu Lee ${ }^{\mathrm{a}}$, Hyun-Man $\mathrm{Oh}^{\mathrm{a}}$, Jae-Gwan Kang ${ }^{\mathrm{b}^{*}}$ \\ ${ }^{a}$ Department of Advanced Engineering, Graduate School of Kyungnam Univ., Republic of Korea \\ ${ }^{b}$ Division of Mechanical Engineering, Kyungnam Univ., Republic of Korea
}

\begin{tabular}{|c|c|c|c|}
\hline \multicolumn{4}{|c|}{ ARTICLE INFO } \\
\hline \multicolumn{4}{|c|}{ Article history: } \\
\hline Received & 16 & August & 2013 \\
\hline Revised & 26 & September & 2013 \\
\hline Accepted & 8 & October & 2013 \\
\hline
\end{tabular}

Keywords:

Incremental sheet metal forming

Positive incremental forming

Negative incremental forming

Forming shape error

Surface roughness

\begin{abstract}
Incremental forming of sheet metal is a modern method of forming sheet metal, where parts can be formed without the use of dedicated dies. Existing experimental configurations for incremental forming can be broadly classified into two categories, i.e., negative and positive forming. In this paper, forming qualities such as shape accuracy and surface roughness of Al 1050 material were discussed for different forming methods. The formed and the corresponding opposing surfaces were measured with a three-dimensional scanner and a surface roughness tester. It was found that in terms of shape accuracy, the best opposing surface was obtained with positive forming, whereas the worst formed surface was obtained with negative forming; furthermore, the opposing surface is always better than the formed surface, regardless of the forming method used.
\end{abstract}

\section{1. 서 론}

항공기, 자동차, 선박 등의 외장품은 다양한 3차원 곡면 형태를 갖는 금속 판재물로 제작되는 경우가 많다. 3 차원 곡면 형상의 제 품을 성형하는 방법으로는 프레스 공법이 전통적으로 사용된다.

기존의 프레스 공법은 성형하고자 하는 형상의 상·하 금형을 사 용한다. 이러한 프레스 공법은 대량생산에는 적합하지만 소량생산 의 경우에는 금형의 설계와 금형의 상·하 제작에 많은 시간과 비용 이 소요된다. 이를 극복하기 위해 상-하 금형을 사용하지 않고 금속 판재물을 성형할 수 있는 무금형 점진 판재 성형공법(이하 점진성 형공법)이 개발되어 활용 되고 있다 ${ }^{[1-2]}$.

* Corresponding author. Tel.: +82-55-249-2703

$$
\text { Fax: }+82-55-999-2130
$$

E-mail address: jkkang@kyungnam.ac.kr (Jae-Gwan Kang).
점진성형이란 설계형상의 $3 \mathrm{D} \mathrm{CAD}$ 정보로부터 점진성형에 관 한 등고선 공구경로를 추출하고 판재물을 플레이트에 고정시킨 후 $\mathrm{CNC}$ 제어를 이용하여 점진적으로 성형하는 방법이다. 점진성형 공법의 개발로 인하여 다품종 소량 생산에서 금형 상·하의 설계와 제작에 따른 비용 및 시간을 획기적으로 줄일 수 있고 프레스 공법 에서 발생하는 소음과 진동이 없으며 형상을 변경할 경우 금형을 새로 제작할 필요 없이 $3 \mathrm{D} \mathrm{CAD}$ 형상의 변경으로 간단한 수정이 가능한 장점이 있다. Fig. 1에 점진성형으로 성형한 다양한 금속 판재물의 모습이 나타나 있다.

점진성형의 방법에는 음각점진성형(Negative incremental forming) 과 양각점진성형(Positive incremental forming)이 있다 ${ }^{[3]}$. 
음각점진성형은 판재 하단에 아무것도 설치하지 않거나 Fig. 2 와 같이 함몰형으로 서포터를 만든 후 판재의 윤곽 부위부터 점진 적으로 성형하여 최종 형상을 만드는 방법이다.

이에 반하여 양각점진성형은 Fig. 3과 같이 돌출형으로 제작된 서포터 위에 판재를 올려놓고 형상물의 중심 부위부터 외곽으로 점진성형 하는 방법으로 작업베드가 상하 운동을 할 수 있는 가이 드 장치와 일정한 압력을 유지하게 하는 공압 장치 등이 부가적으 로 필요하다.

그러므로 음각점진성형은 기존의 $\mathrm{CNC}$ 밀링 머신 또는 머시닝 센터에 간단하게 구현할 수 있는 반면 양각점진성형을 위해서는 공압으로 구동되는 전용 작업베드 등의 설치에 추가적인 비용이 소요되게 된다.

점진 성형에 있어 가장 큰 문제점은 성형 이후의 정밀도 문제이 다. 프레스 공법과 달리 국부적인 소성가공의 원리에 의한 점진성 형공법은 성형 후의 스프링백(spring back), 그리고 공구 자국(tool mark) 등에 의하여 많은 성형 정밀도 문제가 발생하기 때문에 점 진성형 조건에 따른 성형 품질 문제에 대하여 많은 연구가 이루어
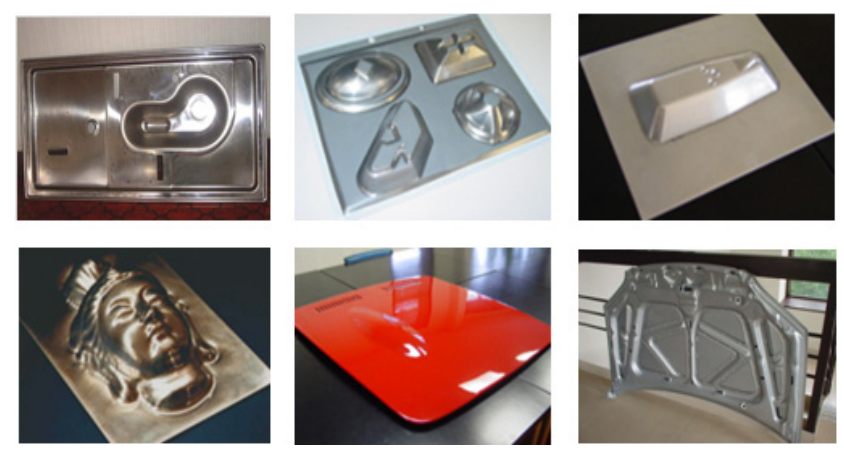

Fig. 1 Various incremental forming products

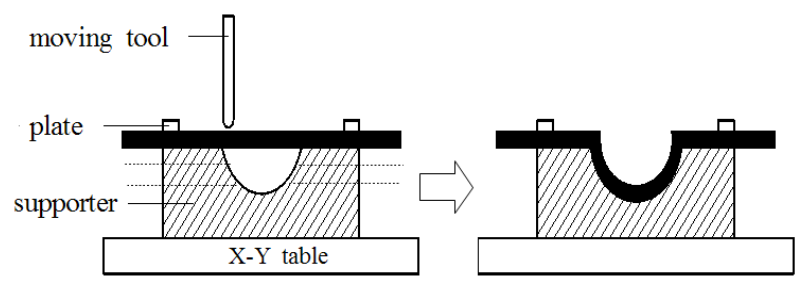

Fig. 2 Negative incremental forming

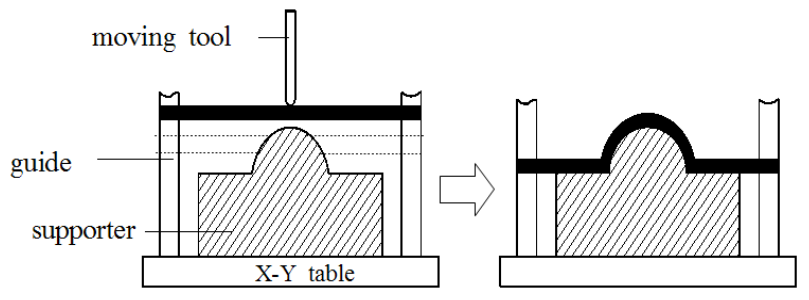

Fig. 3 Positive incremental forming
져 왔다 ${ }^{[4-8]}$. 기존 논문 ${ }^{[9]}$ 에서는 양각 성형공법으로 성형한 제품이 음각 성형공법보다 성형 품질이 더 우수하다고 서술하고 있지만 정량적인 연구 결과는 명시되어 있지 않다.

음각과 양각성형 공법은 사용자가 선택할 수 있는 점진성형의 유일한 두가지 방법임을 고려할 때 공정계획(process planning)의 측면에서 각 성형 방법에 따른 성형 정밀도 차이를 규명하는 것은 매우 중요하다.

따라서 본 연구에서는 양각 점진성형과 음각 점진성형의 두 성형 공법에 따른 성형 품질, 즉 성형 정밀도를 비교 분석하고자 한다. 동일한 샘플 형상에 대하여 두가지 성형공법으로 성형한 후 직접 성형면(formed surface)과 성형 반대면(opposite surface)의 성형 물의 형상 오차와 표면거칠기 비교 등을 실시하였다.

\section{2. 점진성형의 실험}

\section{1 실험 장치}

양각 점진성형과 음각 점진성형은 Fig. 4에 나타나 있는 $\mathrm{CNC}$ 포밍 전용머신(AMINO사의 DLNC-PA)을 이용하여 실험하였다. DLNC-PA는 기본적으로 양각 성형을 제공하지만 양각 성형용 치 구를 이용하지 않을 경우 음각 성형도 가능하다. 사용된 $\mathrm{CNC}$ 포밍 머신의 구체적인 사양은 Table 1과 같다.

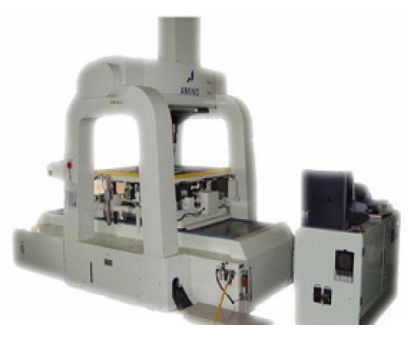

Fig. 4 Incremental forming machine(DLNC-PA)

Table 1 Incremental forming machine specifications

\begin{tabular}{c|c}
\hline \hline Items & Spec. \\
\hline Max blank size $(\mathrm{mm})$ & $1,100 \times 900 \mathrm{~mm}$ \\
\hline Max forming size $(\mathrm{mm})$ & $1,000 \times 900 \mathrm{~mm}$ \\
\hline Max forming depth $(\mathrm{mm})$ & $300 \mathrm{~mm}$ \\
\hline
\end{tabular}
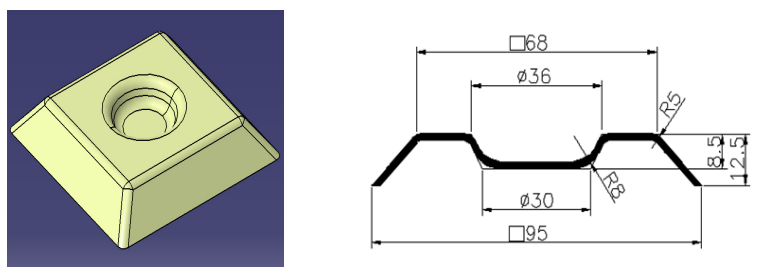

Fig. 5 CAD model used for the experiment 


\section{2 실험용 포밍 형상}

본 연구에서 사용된 실험용 포밍 형상의 모습이 Fig. 5에 나타나 있다. 실험용 형상에는 금속판재물을 구성하는 특징형상들인 경사 면과 볼록, 오목 등의 요철이 포함되도록 하였다.

\section{3 포밍 과정}

앞서 설명한 점진 성형의 절차에 따라 $\mathrm{CNC}$ 포밍 전용 머신으로 양각 점진성형을 실시하였다. 점진성형의 조건이 Table 2에 나타 나 있다.

공구는 직경 $10 \mathrm{~mm}$ 볼 타입의 점진성형 공구, 이송속도는 $1,000 \mathrm{~mm} / \mathrm{min}$, 성형깊이는 $0.3 \mathrm{~mm}$ 로 하였다. 소재는 연성이 좋 은 $\mathrm{Al} 1050$, 두께 $1.5 \mathrm{~mm}$ 를 사용하였다.

음각 점진성형을 하고 있는 모습이 Fig. 6에 나타나 있다. 음각 성형 시에는 판재물 하단에 음각으로 가공된 서포터를 두고 $\mathrm{z}$ 축을 따라 등고선 공구경로로 점진성형하게 된다.

Fig. 7은 동일한 성형 조건으로 양각 성형을 하는 모습이다. 케미 컬 우드를 이용하여 양각으로 가공된 서포터를 설치하고 판재를 올린 다음 $\mathrm{z}$ 축을 따라 등고선 공구경로로 점진성형을 하게 된다.

음각성형의 경우에는 공구경로가 외곽에서 안쪽으로, 양각성형

Table 2 Forming conditions

\begin{tabular}{c|c}
\hline \hline Items & Conditions \\
\hline Tool & Ball type $\varnothing 10 \mathrm{~mm}$ \\
\hline Feed & $1,000 \mathrm{~mm} / \mathrm{min}$ \\
\hline Forming depth & $0.3 \mathrm{~mm}$ \\
\hline Material, thickness & Al $1050,1.5 \mathrm{t}$ \\
\hline
\end{tabular}

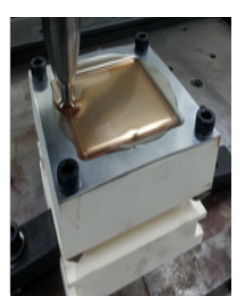

(a) start

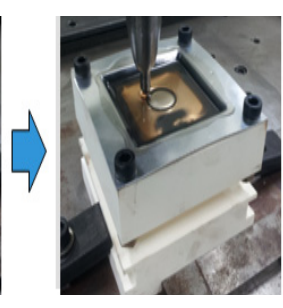

(b) half

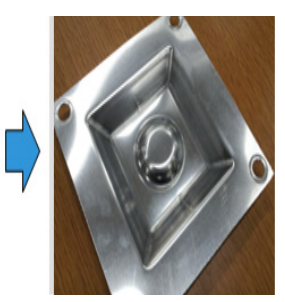

(c) finish
Fig. 6 Negative incremental forming processes

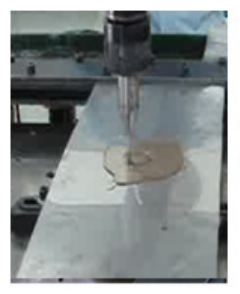

(a) start

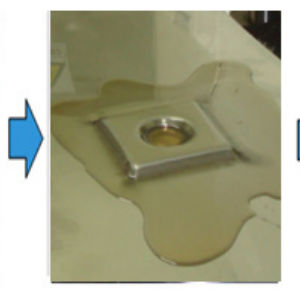

(b) half

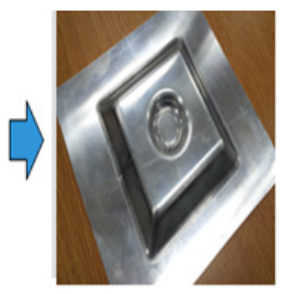

(c) finish
Fig. 7 Positive incremental forming processes
에서는 중심에서 바깥쪽으로 공구경로가 형성되는 것이 차이점이 다. 그리고 음각성형의 경우에는 Fig. 6 에서 보는 바와 같이 서포터 에 직접 소재를 클램핑시키지만 양각성형의 경우에는 서포터 외부 에 공압으로 지지되는 별도의 클램핑 장치를 사용하게 된다.

\section{3. 성형 정밀도 분석}

본 연구에서는 성형 정밀도를 형상 정밀도(shape accuracy)와 표면거칠기(surface roughness)로 분류하고 성형결과물에 대하여 직접 성형이 이루어진 성형면(formed surface)과 성형반대면 (opposite formed surface)에 대하여 측정을 실시하였다.

\section{1 형상 정밀도의 비교}

먼저 성형 결과물에 대하여 Reneshaw사의 접촉식 3차원 스캐 너인 Cyclone을 이용하여 스캔데이터를 획득하였다. 그리고 형상 오차 분석에는 스캔데이터 분석 전용 소프트웨어인 Rapidform$\mathrm{XOV}$ 를 사용하였다.

Fig. 8과 같이 네 개의 단면(Sec-1,2,3,4)에 대하여 오차를 측정
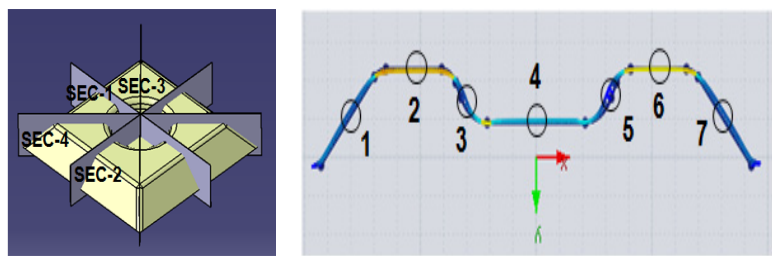

(a) PFS(Positive Formed Surface)
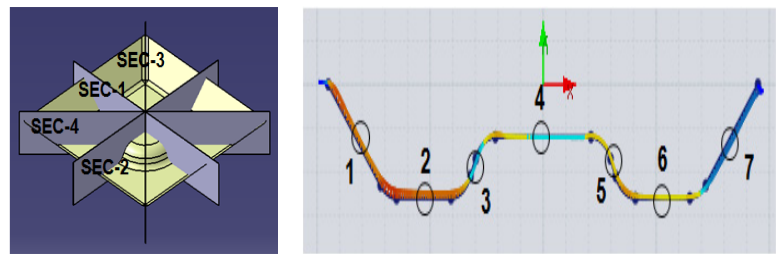

(b) POS(Positive Opposite formed Surface)
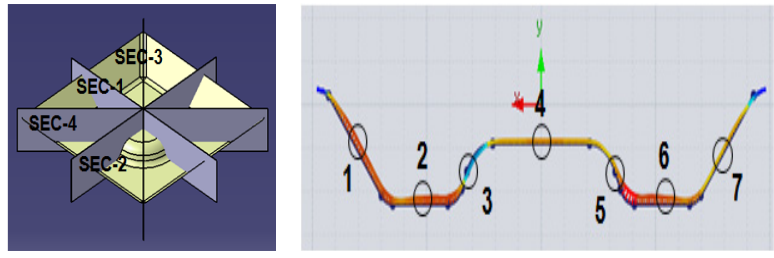

(c) NFS(Negative Formed Surface)
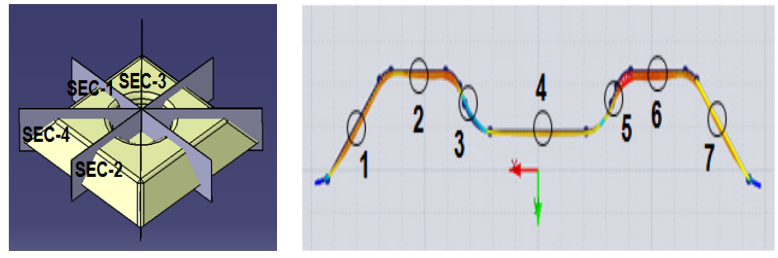

(d) NOS(Negative Opposite formed Surface)

Fig. 8 Analysis of forming shape emors 
하였으며 각 단면에서는 7개의 영역에서 오차를 추출하여 평균값 을 계산하였다. 양각성형면(PFS : Positive Formed Surface)과 반대면(POS : Positve Opposite formed Surface), 음각성형면 (NFS : Negative Formed Surface)과 반대면(NOS : Negative Opposite formed Surface)에 대하여 계산된 결과 값을 Table 3에 정리하였다.

실험계획법은 효울적인 실험방법을 설계하고 결과를 분석하는 것을 목적으로 절삭가공은 물론 점진성형 연구에서도 성형조건이 결과에 미치는 영향을 알아보기 위하여 많이 활용되고 있는 통계학 의 응용분야이다 ${ }^{[10-12]}$.

실험결과 데이터에 대하여 실험계획법의 일원배치 분산분석 (ANOVA)을 실시한 결과가 Table 4에 나타나 있다. 분산분석 결

Table 3 Result of forming emors

\begin{tabular}{c|c|c|c|c}
\hline \hline \multirow{2}{*}{ SEC. } & \multicolumn{2}{|c|}{ Positive forming } & \multicolumn{2}{c}{ Negative forming } \\
\cline { 2 - 5 } & $\begin{array}{c}\text { formed } \\
\text { surface } \\
\text { (PFS) }\end{array}$ & $\begin{array}{c}\text { opposite } \\
\text { surface } \\
\text { (POS) }\end{array}$ & $\begin{array}{c}\text { formed } \\
\text { surface } \\
\text { (NFS) }\end{array}$ & $\begin{array}{c}\text { opposite } \\
\text { surface } \\
\text { (NOS) }\end{array}$ \\
\hline SEC-1 & $0.48 \mathrm{~mm}$ & $0.39 \mathrm{~mm}$ & $0.54 \mathrm{~mm}$ & $0.40 \mathrm{~mm}$ \\
\hline SEC-2 & $0.49 \mathrm{~mm}$ & $0.35 \mathrm{~mm}$ & $0.49 \mathrm{~mm}$ & $0.39 \mathrm{~mm}$ \\
\hline SEC-3 & $0.34 \mathrm{~mm}$ & $0.37 \mathrm{~mm}$ & $0.63 \mathrm{~mm}$ & $0.53 \mathrm{~mm}$ \\
\hline SEC-4 & $0.38 \mathrm{~mm}$ & $0.37 \mathrm{~mm}$ & $0.62 \mathrm{~mm}$ & $0.49 \mathrm{~mm}$ \\
\hline $\begin{array}{c}\text { Avg. } \\
\text { error }\end{array}$ & $0.42 \mathrm{~mm}$ & $0.37 \mathrm{~mm}$ & $0.57 \mathrm{~mm}$ & $0.45 \mathrm{~mm}$ \\
\hline
\end{tabular}

Table 4 ANOVA table for forming emors

\begin{tabular}{c|c|c|c|c|c}
\hline \hline Source & DF & SS & MS & F & P \\
\hline Level & 3 & 0.08603 & 0.02868 & 7.69 & 0.004 \\
\hline $\begin{array}{c}\text { Residual } \\
\text { error }\end{array}$ & 12 & 0.04475 & 0.00373 & - & - \\
\hline Total & 15 & 0.13078 & - & - & - \\
\hline
\end{tabular}

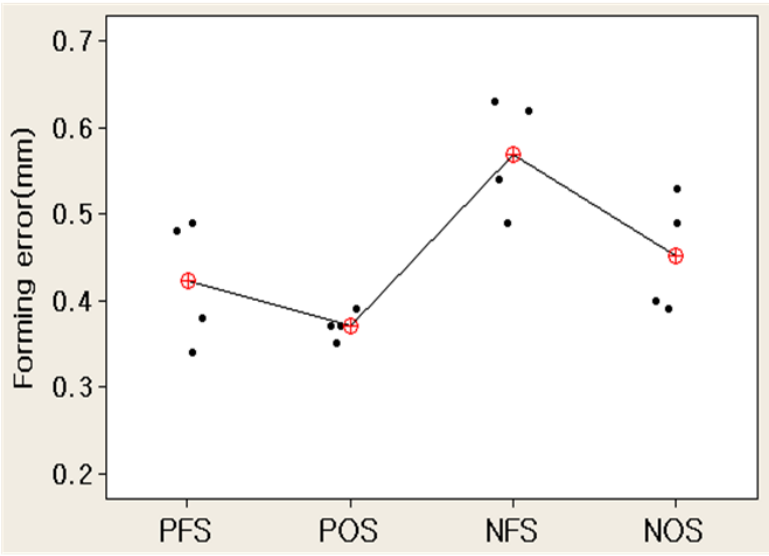

Fig. 9 Individual plot of forming emors
과 음.양각 성형 방법에 따라 직접 성형면과 반대면의 형상정밀도 에는 유의한 차이가 있는 것으로 나타났다 ( $\mathrm{p}$-value $=0.004)$.

Fig. 9는 Table 3의 양각성형면과 반대면, 음각성형면과 반대면 의 정밀도 값을 그래프로 표현한 모습이다. 형상오차 평균값으로 보았을 때 $\mathrm{POS}>\mathrm{PFS}>\mathrm{NOS}>\mathrm{NFS}$ 순으로 형상 정밀도가 우수 한 것으로 나타났다.

그러나 측정 오차 등을 고려할 때 양각성형 반대면(POS)의 형상 정밀도가 가장 우수 $(0.37 \mathrm{~mm})$ 하고, 음각 성형면(NFS)의 형상 정 밀도가 가장 나쁜 것 $(0.57 \mathrm{~mm})$ 은 확실하다고 할 수 있으나 양각성 형면(PFS, $0.42 \mathrm{~mm}$ )과 음각 성형 반대면(NOS, $0.45 \mathrm{~mm})$ 의 우 열관계는 $\mathrm{p}$-value $=0.574$ 로서 통계적으로 유의하다고 결론지을 수 없다.

그리고 양각성형에서도 성형의 반대면(POS)이 성형을 직접한 면(PFS)보다 형상 정밀도가 좋으며, 음각에서도 성형의 반대면 $(\mathrm{NOS})$ 이 성형을 직접한 면(NPS)보다 형상 정밀도가 좋은 것으로 나타났지만 각각의 $\mathrm{p}$-value값이 0.210 과 0.049 로 후자의 경우만 통계적으로 유의하다고 말할 수 있다.

\section{2 표면 거칠기의 비교}

표면거칠기는 Fig. 4와 같이 실험용 형상의 경사면에 대해서만 측정하였다. 윤곽을 따라 등고선 공구경로를 사용하는 점진 성형의 특징 상 바닥면의 경우에는 포밍이 이뤄지지 않아 표면 거칠기에 변화가 없다. KOSAKA사의 SEF 3500 조도 측정기가 이용되었 다. 측정 방법은 Fig. 10 과 같이 양각성형면(PFS)과 반대면(POS), 음각성형면(NFS)과 반대면(NOS)에 대하여 네 개의 영역에서 측 정을 하였으며 중심선 평균 거칠기 $(\mathrm{Ra})$ 값을 사용하였다.

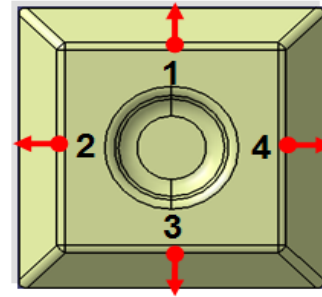

(a) PFS

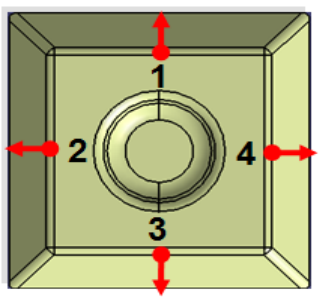

(c) NFS

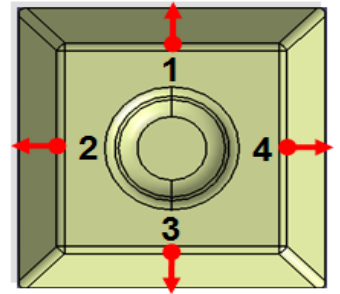

(b) POS

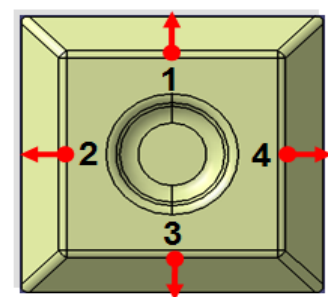

(d) NOS
Fig. 10 Surface roughness measurement strategies 
Table 5 Results of surface roughness measurement

\begin{tabular}{|c|c|c|c|c|c|}
\hline & \multirow{2}{*}{$\begin{array}{l}\text { Before } \\
\text { forming }\end{array}$} & \multicolumn{2}{|c|}{ Positive forming } & \multicolumn{2}{|c|}{ Negative forming } \\
\hline & & $\begin{array}{l}\text { formed } \\
\text { surface }\end{array}$ & $\begin{array}{l}\text { opposite } \\
\text { surface }\end{array}$ & $\begin{array}{l}\text { formed } \\
\text { surface }\end{array}$ & $\begin{array}{l}\text { opposite } \\
\text { surface }\end{array}$ \\
\hline 1 & & $1.03 \mu \mathrm{m}$ & $0.98 \mu \mathrm{m}$ & $1.21 \mu \mathrm{m}$ & $0.83 \mu \mathrm{m}$ \\
\hline 2 & & $0.82 \mu \mathrm{m}$ & $0.53 \mu \mathrm{m}$ & $0.90 \mu \mathrm{m}$ & $0.72 \mu \mathrm{m}$ \\
\hline 3 & & $0.80 \mu \mathrm{m}$ & $0.90 \mu \mathrm{m}$ & $0.82 \mu \mathrm{m}$ & $0.42 \mu \mathrm{m}$ \\
\hline 4 & & $0.80 \mu \mathrm{m}$ & $0.47 \mu \mathrm{m}$ & $0.92 \mu \mathrm{m}$ & $0.48 \mu \mathrm{m}$ \\
\hline $\begin{array}{l}\text { Total } \\
\text { Avg. } \\
\text { error }\end{array}$ & $0.20 \mu \mathrm{m}$ & $0.86 \mu \mathrm{m}$ & $0.72 \mu \mathrm{m}$ & $0.96 \mu \mathrm{m}$ & $0.61 \mu \mathrm{m}$ \\
\hline
\end{tabular}

Table 6 ANOVA table for surface roughness values

\begin{tabular}{c|c|c|c|c|c}
\hline \hline Source & DF & SS & MS & F & P \\
\hline Level & 3 & 0.2857 & 0.0952 & 2.61 & 0.099 \\
\hline $\begin{array}{c}\text { Residual } \\
\text { error }\end{array}$ & 12 & 0.4370 & 0.0364 & - & - \\
\hline Total & 15 & 0.7227 & - & - & - \\
\hline
\end{tabular}

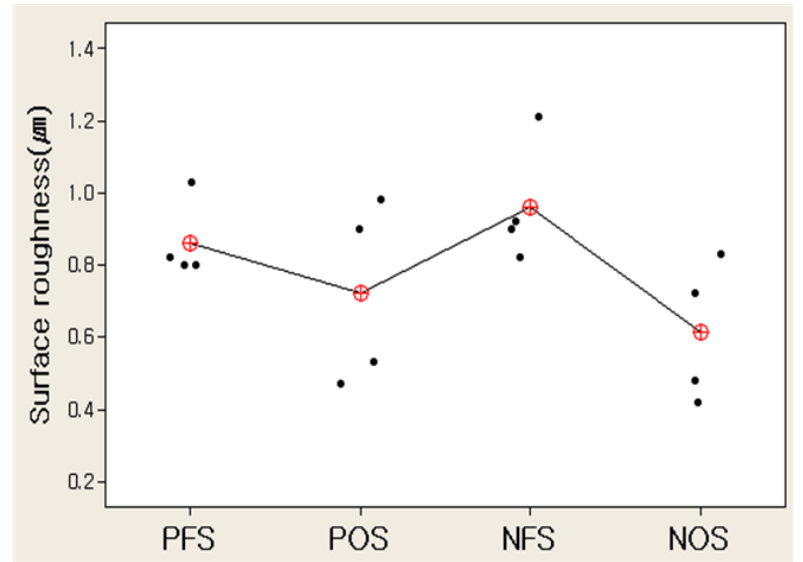

Fig. 11 Individual plot of measured surface roughness

측정 결과값이 Table 5에 나타나 있다. 단, 성형전의 소재 표면 거칠기 값은 $0.20 \mu \mathrm{m}$ 이었다.

표면거칠기 측정 결과값에 대하여 일원배치 분산분석(ANOVA) 을 실시한 결과 Table 6 과 같이 유의수준 $10 \%$ 에서 각 성형 방법에 따라 표면 거칠기는 다른 것으로 나타났다. p-value $=0.099$ 는 유의 수준이 $10 \%$ 정도를 의미하며 수준에 따라 표면 거칠기의 값이 다 르다고 단언할 수는 없지만 어느 정도는 차이가 있음을 나타낸다.

Fig. 11은 각각의 성형 결과물의 정밀도에 대한 개별 값 플롯을 보여주고 있다. 각 수준 평균간의 차이보다 각 수준에서의 표면거 칠기 값의 산포가 큰 것을 볼 수 있다.

각 수준간의 표면거칠기를 비교하면 음각성형 반대면(NOS)의
$\mathrm{Ra}$ 값 $(0.61 \mu \mathrm{m})$ 이 가장 좋은 것으로 나타났으며 반대로 직접 공구 가 접촉한 음각성형면 $(\mathrm{NFS})$ 의 $\mathrm{Ra}$ 값 $(0.96 \mu \mathrm{m})$ 이 가장 나뺀 것으로 나타났다. 이 두 수준간의 차이에 대한 $\mathrm{p}$-value 값은 0.035 이다. 그러나 Table 5 에서 음각성형의 반대면의 표면거칠기 $(\mathrm{NOS}=0.61$ $\mu \mathrm{m})$ 이 양각성형의 반대면( $\mathrm{POS}=0.72 \mu \mathrm{m})$ 보다 좋은 것으로 나타났 지만 통계적으로는 유의하다고 할 수 없었다(p-value $=0.53)$.

다만, 양음각 모두 공구가 직접 접촉하는 성형면(formed surface) 이 반대면(opposite surface)보다 표면거칠기 값이 크게 나타났으며 음각성형 $(0.96-0.61=0.35 \mu \mathrm{m})$ 의 경우 양각성형 $(0.86-0.72=0.14 \mu \mathrm{m})$ 에 비해 그 차이가 더 컸다.

그리고 성형 반대면의 경우 공구가 직접 접촉하지 않았음에도 불구하고 성형 완료 후 원소재의 표면거칠기값 $(0.20 \mu \mathrm{m})$ 값보다 약 4 배 이상 나빠지는 것 $(\mathrm{POS}=0.72 \mu \mathrm{m}, \mathrm{NOS}=0.96 \mu \mathrm{m})$ 으로 나타났 다. 이는 성형과정 중에 성형을 지지하는 서포터와 마찰이 발생하 고 사용된 소재 두께(1.5t)가 상대적으로 얇아서 성형의 영향이 반 대면까지 미쳤기 때문으로 판단된다.

\section{4. 결 론}

본 연구는 점진성형의 두 가지 방법인 양각 점진성형과 음각 점 진성형의 성형 정밀도 비교에 관한 연구로서 원하는 형상에 대하여 어떤 성형 공법을 적용하는 것이 좋은가를 판단하기 위하여 수행되 었다.

먼저 형상 정밀도 측면에서는 양각 점진성형이 음각 점진성형보 다 우수한 것으로 나타났다. 상세하게는 양각성형 반대면(POS) > 양각 성형면 $(\mathrm{PFS})>$ 음각성형 반대면 $(\mathrm{NOS})>$ 음각성형면(NFS) 의 순으로 형상 정밀도가 좋았다. 다만 양각 성형면(PFS)과 음각 성형 반대면(NOS) 간에는 통계적으로 유의한 차이를 보이지 않았다.

두 번째, 표면거칠기 측면에서는 음각 성형반대면(NOS) > 양각 성형반대면(POS) > 양각 성형면(PFS) > 음각 성형면(NFS)의 순 으로 표면거칠기가 양호한 것으로 나타났다. 단, 음각성형 반대면 (NOS)과 양각 성형 반대면(POS) 간의 우열은 통계적으로 확인할 수 없었다. 그러나 성형 방법과 상관없이 공구와 직접 접촉하지 않 는 포밍 반대면은 포밍 면보다 항상 표면거칠기가 우수하였으나 원 소재의 표면거칠기 $(0.20 \mu \mathrm{m})$ 에 비해서는 4 배 이상 표면 거칠기 가 저하되는 것으로 나타났다.

이로부터 주어진 형상에 대하여 성형 공법을 선택할 경우 가능하 면 양각성형을 한 뒤 성형 뒷면을 주요한 형상 부위로 사용하는 것이 좋으며 음각성형의 직접 성형 면은 가능하면 주요 형상 부위 로 사용하는 것을 피하는 것이 좋다고 말할 수 있다. 


\section{References}

[1] Matsubara S., 2001, A Computer Numerically Controlled Dieless Incremental Forming of a Sheet Metal, Proc. Instn. Mech. Engrs. 215 Part B 959-966.

[2] Shim, M. S., Park, J. J., 2001, Deformation Characteristics in Sheet Mental Forming with Small Ball, Trans. Mater. Process. 10:1 59-66.

[3] Allwood, J. M., Bramley, A. N., Ridgman, Mileham, A. R., 2006, A novel method for the rapid production of inexpensive dies and moulds with surfaces made by incremental sheet forming, Proc. Instn. Mech. Engrs. 220:2 Part B 323-327.

[4] Ambrogio, G., Costantino, I., De Napoli, L., Filice, L., Fratini, L., Muzzupappa, M., 2004, Influence of some relevant process parameters on the dimensional accuracy in incremental forming: a numerical and experimental investigation, J. Mater. Process. Technol. 153:154 501-507.

[5] Ham, M., Jeswiet, J., 2008, Dimensional Accuracy of Single Point Incremental Forming, Int. J. Mater. Form. 1: 1171-1174.

[6] Radu, M. C., Cristea, I., 2013, Processing Metal Sheets by SPIF and Analysis of Parts Quality, Mater. and Manuf. Process. 28: 287-293.

[7] Song, X., Lu, B., Chen, J., Wang, Y., 2013, Influencing Factor Analysis on the Surface Quality of Incremental Forming Parts, J. Mech. Eng. 49:8 84-90.

[8] Micari, F., Ambrogio, G., Filice, L., 2007, Shape and dimensional accuracy in Single Point Incremental Forming: State of the art and future trends, J. Mater. Process. Technol 191 390-395.

[9] Hirt, G. and Ames, J., 2004, Forming strategies and Process Modelling for CNC Incremental Sheet Forming, CIRP Ann. 53:1 203-206.

[10] Ham, M. and Jeswiet, J., 2006, Single Point Incremental Forming and the Forming Criterial for AA3003, CIRP Ann. 55:1 241-244.

[11] Kang, S. K, 2012, Analysis of Effects of Cutting Force and Surface Roughness in the Cutting Conditions of Plasma Source Ion Implantation Tools, J. of Korean Soc. of Manuf. Technol. 21:5 755-760.

[12] Lee, S. P., Ha, S. K., 2008, Performance Evaluation for Coordinate Measuring Machine using Design of Experiments, Trans. of Korean Soc. of Mach. Tool Engrs. 17:4 133-139. 